\title{
Effect of PEG and mannitol to induce drought stress on seed quality and stand establishment in wheat (Triticum aestivum L.) genotypes
}

\author{
S. B. Patil* and Jitendra Kumar S. Hilli ${ }^{1}$ \\ Department of Seed Science and Technology, Agriculture Research Station, Konnur (Karnataka) India \\ (Email: patilsb13520@uasd.in)
}

\begin{abstract}
An experiment was conducted to study the screening of wheat (Triticum aestivum L.) genotypes for drought tolerance under laboratory condition during2018 at Department of Seed Science and Technology, College of Agriculture, Vijayapura. The experiment was carried out in a factorial Complete Randomized Block Design with seven treatments replicated three times. Twenty six wheat genotypes were screened for drought tolerance using 0, 15, 30, 60 per cent polyethylene ethylene glycol 6000 (PEG6000) and 1, 2, 5 per cent mannitol solutions. Data were recorded on various seedling parameters like germination percentage, root length, shoot length, seedling dry weight and seedling vigour index. The seedling traits showed a decreasing trend in response to increased concentrations of PEG6000 and mannitol. Wheat genotype DBW-110 (98.70\%) and C-306 (92.50\%) were found to be the best genotype for screened based on germination percentage at 15 per cent PEG6000 and 5 per cent mannitol. Wheat genotypes HI-1620 $(6.7 \mathrm{~cm})$ and NIAW-3212 $(4.5 \mathrm{~cm})$ produced maximum root length, respectively at higher concentrations of PEG6000 and mannitol. The genotype HI-1620(6.4 cm,@15\%; $5.4 \mathrm{~cm}, @ 5 \%$ mannitol) showed maximum shoot length. The genotype HD-2733, DBW-14, DBW-88 showed highest reduction of seedling parameters observed at increase in osmotic stress condition.
\end{abstract}

Key Words : Drought, Polyethylene glycol, Mannitol, Wheat, Genotypes

View Point Article : Patil, S.B. and Hilli, Jitendra Kumar S. (2021). Effect of PEG and mannitol to induce drought stress on seed quality and stand establishment in wheat (Triticum aestivum L.) genotypes. Internat. J. agric. Sci., 17 (2) : 469-475, DOI:10.15740/HAS/IJAS/17.2/ 469-475. Copyright@2021: Hind Agri-Horticultural Society.

Article History : Received : 01.03.2021; Revised : 04.03.2021; Accepted : 17.03.2021

\footnotetext{
* Author for correspondence :

${ }^{1}$ University of Agricultural Sciences, Dharwad (Karnataka) India
} 